\title{
Correspondence
}

Editor: Greg Wilkinson

Contents: Late paraphrenia or the paraphrenias?/ Failure to convulse with electroconvulsive therapy/ Hypomania and epilepsy/Hypomania following complex partial seizures/Diethylpropion hydrochloride-induced psychosis/The place of benzodiazepines in psychiatric practice/Neurosyphilis and psychiatry/Heterogeneity in sporadic schizophrenia/ Deliberate self-harm and out-patient attendance/ The BITE: indices of agreement/Standardised assessment of personality disorder in mental handicap/ Behaviourally disturbed HIV patients/The pathogenesis of depersonalisation: a hypothesis/'Neuroleptic malignant syndrome' without neuroleptics/ Clastogenic factors and abnormal plasma fractions in a female patient with severe aggressiveness/Atypical koro/Successful treatment of a Chinese with primary ejaculatory failure/Bipolar affective disorder and thalassaemia minor - a genetic linkage?/"Affective Disorders in the Elderly".

\section{Late Paraphrenia or the Paraphrenias?}

SIR: I would like to reply to the criticism of the above study (Journal, May 1987, 150, 635-639) by Grahame (Journal, August 1987, 151, 268-269 and Journal, February 1988, 152, 289). Sadly, I feel that his letters typify the polemical arguments which have dogged the subject for so long.

My study should not be confusing. To satisfy the proponents of the narrower 'late paraphrenia' definition of Kay \& Roth (1961) and those who prefer the wider concept of the "persistent persecutory states in the elderly' approach of Post (1966), I used both independently when I reviewed the ten-year outcome of 47 elderly patients diagnosed initially by Maudsley Hospital clinicians as suffering from functional paranoid psychoses. The results gave much support to the liberal concept of 'organicity' as included in DSMIII. Whatever Dr Grahame's "suspicions" that "the organic group could have been identified at the time of initial contact", the fact was that they were not, even though they underwent thorough assessment at the time.

Dr Grahame sees 'late paraphrenia' as a homogeneous clinical syndrome which "is one of the schizophrenias". He quotes his own study (Grahame,
1984) as evidence. I have serious reservations about the interpretation of his findings, as do Levy \& Naguib (Journal, April 1985, 146, 451, and Journal, November 1987, 151, 702). I would agree, however, with his statement in his paper that "it is highly likely that schizophrenia will turn out to be a syndrome... with multiple aetiologies". If this point is accepted, there seems little argument about my assertion that 'late paraphrenia' is a syndrome which similarly has multiple aetiologies.

In these letters of argument over the homogeneity of 'late paraphrenia', the term 'organic brain syndrome' is being used as if it too might be a homogeneous entity. DSM-III lists and defines ten organic brain syndromes, of which organic delusional syndrome or organic personality syndrome are perhaps most relevant to this discussion. However, confusion will arise if the wider term is used without specifying to what it refers.

It seems that Dr Grahame is unsure of his own views; having criticised my paper in his first letter, in his second letter he goes on to acknowledge that I give support to his hypothesis. I cannot help but feel that his distasteful and unnecessary personalisation of his arguments, and his views on De Crispigny Park and Colchester, reveal more about his own personal prejudice than they add to the academic debate.

Finally, I would like to point out that Dr Grahame persists in inaccurately quoting a study by "Blessed \& Christie (1982)", which does not exist, and should read Blessed \& Wilson (1982).

\section{Mapperley Hospital \\ Porchester Road \\ Nottingham}

N. L. HOLDEN

\section{References}

Blessed, G. \& WILSON, I. D. (1982) The contemporary natural history of mental disorder in old age. British Journal of Psychiatry, 141, 59-67.

GRAHAME, P. S. (1984) Schizophrenia in old age (late paraphrenia). British Journal of Psychiatry, 145, 493-495.

KAY, D. W. K. \& Roth, M. (1961) Environmental and hereditary factors in the schizophrenia of old age (late paraphrenia) and their bearing on the general problem of causation in schizophrenia. Journal of Mental Science, 107, 649-686.

Post, F. (1966) Persistent Persecutory States of the Elderly. Oxford: Pergamon Press. 